Musées, Patrimoine et Culture scientifiques et techniques

$173 \mid 2017$

septembre-octobre 2017

\title{
Le musée réinventé
}

\section{François Mairesse}

URL : http://journals.openedition.org/ocim/1860

DOI : 10.4000/ocim. 1860

ISSN : 2108-646X

\section{Éditeur}

OCIM

Édition imprimée

Date de publication : 1 septembre 2017

Pagination : 34-35

ISSN : 0994-1908

Référence électronique

François Mairesse, "Le musée réinventé », La Lettre de l'OCIM [En ligne], 173 | 2017, mis en ligne le 01 septembre 2018, consulté le 01 mai 2019. URL : http://journals.openedition.org/ocim/1860 ; DOI : 10.4000/ocim.1860

Ce document a été généré automatiquement le 1 mai 2019.

Tous droits réservés 


\section{Le musée réinventé}

\section{François Mairesse}

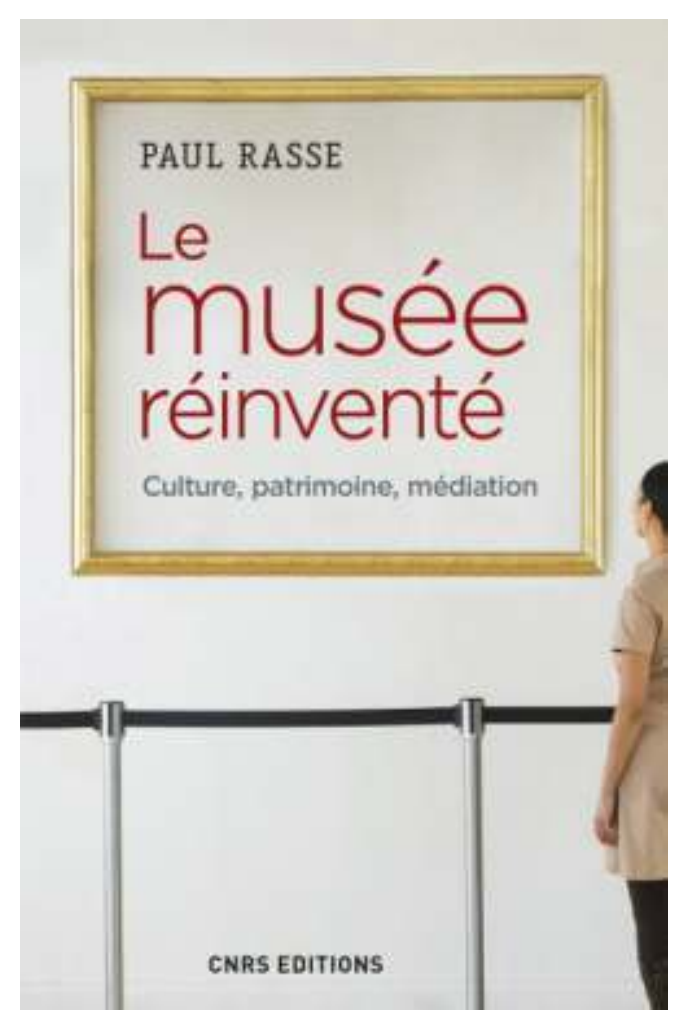

1 On ne peut que se réjouir du fait que le CNRS ait accepté de publier l'ouvrage de Paul Rasse sur l'évolution du phénomène muséal et ses transformations actuelles. Plusieurs ouvrages de cet auteur constituent des jalons de la littérature francophone sur les musées, notamment Techniques et cultures au musée (1997) et Le musée à la lumière de l'espace public (1999). Récemment, Paul Rasse coordonnait avec Yves Girault un important numéro de la revue Hermès : "Les musées au prisme de la communication" (2011). L'ouvrage publié cette année apparaît partiellement comme la somme de ces diverses réflexions sur le monde muséal. Son programme est pour le moins ambitieux : Le musée réinventé, Culture, patrimoine, médiation se présente comme un essai sur l'histoire du fait muséal au sein de la 
culture, afin de montrer "comment, alors qu'ils paraissaient condamnés par la modernité, ils ont su se réinventer en "média", jusqu'à devenir l'une des institutions culturelles les plus brillantes du moment". L'ouvrage se divise essentiellement en trois parties : une première partie aborde la question de la culture dans son sens large, en évoquant ses différentes conceptions et les relations de pouvoir qui lui sont liées. La seconde partie présente l'évolution des musées, en détaillant leur histoire à partir des différentes catégories qui la composent : musées de beaux-arts, musées d'histoire naturelle et musées de science, musées techniques et de cultures populaires, musées de société et de civilisation. La dernière partie, enfin, présente l'institution en crise et la manière dont celle-ci s'est réinventée à travers les enjeux de communication et de médiation. Autant de chapitres qui pourraient constituer des monographies à part entière et encourent donc le risque d'une certaine superficialité.

2 L'auteur aborde donc successivement, et forcément en les effleurant, les différentes conceptions de la culture (de Bourdieu à Tylor, en passant par Hoggart), puis l'histoire des différentes catégories de musée et la manière dont ceux-ci s'inscrivent comme institution culturelle, depuis le mouseion des Grecs jusqu'à sa métamorphose actuelle après la crise des années 1970. L'ouvrage peut ainsi être lu comme une introduction générale au phénomène muséal contemporain et à sa place dans la culture ${ }^{1}$. L'un de ses mérites est de réserver une part importante des développements sur l'histoire du musée aux institutions scientifiques et techni-qques, trop souvent délaissées au profit des beauxarts. L'auteur souligne avec raison les origines différentes de ces établissements et les

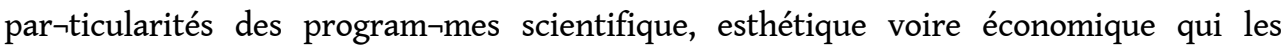
animent. Si les catégories de musées d'art, de sciences et de tech $\neg n i q u e s$ sont reconnues partout dans le monde, Paul Rasse présente également, en un chapitre spécifique, les musées dits de société et de civilisation, apparus plus récemment et dont les contours sont nettement plus flous, même s'ils traduisent un renouveau de la conception du projet muséal. On peut se demander, comme le faisait Noémie Drouguet dans l'ouvrage qu'elle consacre à ce sujet ${ }^{2}$, si le musée de société ne correspond pas plutôt à un nouveau paradigme qu'à une catégorie. C'est d'ailleurs pour cette raison que Paul Rasse, lorsqu'il aborde la crise du musée au chapitre suivant, doit revenir sur l'émergence des écomusées et l'apparition de la nouvelle muséologie, déjà évoquées au chapitre précédent. L'auteur présente la communication comme le principe ayant permis de transformer l'institution, alors en crise au cours des années 1970. Le concept de communication est ainsi pris dans un sens large, intégrant aussi bien l'action culturelle que les développements de la scénographie. Paul Rasse en poursuit l'évocation au chapitre suivant, à travers l'histoire de la médiation, à partir notamment des courants de l'éducation populaire.

On peut regretter que ce panorama de l'histoire muséale, esquissé à grands traits, demeure essentiellement lié à des références francophones. Si les musées français ont souvent joué un rôle majeur dans l'histoire du phénomène, il est dommage que le rôle d'un certain nombre d'institutions majeures - comme le Victoria \& Albert Museum de Londres ou, pour notre époque, le Te Papa Tongarewa Museum de Wellington et, par exemple, les nouveaux musées de Washington (United States Holocaust museum, National museum of African American History and Culture, National Museum of the American Indian) - ne soient évoqués. De manière générale, les développements (plus ou moins) récents de la numérisation au sein des musées, ainsi que leur place actuelle dans l'institution, n'occupent qu'une place minimale dans les deux derniers chapitres consacrés à la communication et à la médiation. 
Paul Rasse se montre optimiste quant au devenir de l'institution muséale : "Dans ce contexte de mutation accélérée des sociétés, les musées séculaires que l’on pensait condamnés par la modernité, ont su se réinventer jusqu'à devenir une institution universelle essaimant sur tous les continents, dans les pays les plus riches comme les plus pauvres, en crise comme en plein essor. [...]. Dans une société de communication où prolifèrent les univers factices et les biens matériels ou immatériels éphémères, ils conservent, pour l'éter-nité, des objets dont ils assurent l'authenticité" (p. 278). Il convient peut-être de modérer cet optimisme. Le phénomène muséal demeure essentiellement occidental (près de $90 \%$ des musées sont situés en Europe et en Amérique du Nord), et si effectivement, le nombre de musées dans le monde ne cesse de croître, de quels musées s'agit-il ? Ces établissements cherchent-ils à assurer l'authenticité des objets et à communiquer du patrimoine? Le musée demeure essentiellement un symbole lié à la richesse d'une société (les musées africains représentent à peine plus de $1 \%$ des musées dans le monde) et s'il s'en crée actuellement un grand nombre dans les pays du Golfe ou en Chine, leur fréquentation par les publics locaux est encore loin d'être assurée. Les différentes appréciations de la notion de patrimoine (notamment le patrimoine immatériel) de même que le fait que certains établissements intitulés "musées" n'abritent pas de collections, comme par exemple au Japon ${ }^{3}$, laissent par ailleurs supposer des évolutions potentiellement divergentes sur la place des musées dans le monde.

\section{NOTES}

1. On regrettera quelques coquilles dans les noms de certains acteurs majeurs (Gustave Gilson, Francis Jeanson ou Georges Henri Rivière et non Gustave Gibson, François Jeanson et GeorgesHenri Rivière).

2. Noémie Drouguet, Le musée de société. De l'exposition de folklore aux enjeux contemporains. Paris : Armand Colin, 2015.

3. Morishita, M. The Empty Museum. Western Cultures and the Artistic Field in Modern Japan. Farnham, Ashgate, 2010.

\section{INDEX}

Mots-clés : Musée, patrimoine, médiation

\section{AUTEUR}

\section{FRANÇOIS MAIRESSE}

professeur, université Paris 3 